\title{
Size-related and geographic variation at two enzyme loci in Megalorchestia californiana (Amphipoda: Talitridae)
}

\author{
John H. McDonald
}

College of Oceanography, Oregon State University, Marine Science Center, Newport, Oregon 97365.

\begin{abstract}
Genetic variation in the enzymes mannose phosphate isomerase and glucosephosphate isomerase was surveyed in the amphipod Megalorchestia californiana Brandt on the Pacific coast of the United States. In a series of samples from Washington state to southern California, both enzyme loci exhibited differences of allele frequency associated with latitude. Geographic differences among nine Oregon samples were not consistently associated with any obvious environmental variable.

Within the Oregon samples, the Mpi locus exhibited a heterozygote deficit in the smallest size class. Larger size classes did not differ from Hardy-Weinberg proportions. Possible explanations for this pattern include genotype-related differences in behavior, growth or viability.
\end{abstract}

\section{INTRODUCTION}

Several types of evidence from natural populations have been used to infer natural selection on enzyme loci. These include associations of allele frequency with environment; deviations from Hardy-Weinberg proportions; differences in allele frequency between sexes or among size or age classes; and temporal changes in allele frequency. Here I examine the loci coding two polymorphic enzymes, mannose phosphate isomerase (MPI, E.C. 5.3.1.8) and glucosephosphate isomerase (GPI, E.C. 5.3.1.9), in the talitrid amphipod Megalorchestia californiana Brandt (formerly Orchestoidea californiana; see Bousfield, 1982).

This species is an appropriate subject for ecological genetics. Individuals remain in burrows or nestled under debris on sand beaches during the day, emerging at night to feed (Bowers, 1964). Because foraging movements are wide ranging and individuals do not return to particular burrows, the amphipods on a beach are a single well mixed population. Juveniles and adults are weak swimmers and avoid water; compared to marine animals with planktonic larvae, there is little dispersal among beaches separated by rocky headlands, river mouths and other barriers. Hundreds of $M$.

Present address: Department of Ecology and Evolution, State University of New York, Stony Brook, New York 11794. californiana are present per linear meter of beach (Bowers, 1964), making large samples possible. In California, breeding occurs from early spring through late autumn (McClurkin, 1953; Bowers, 1964).

\section{MATERIALS AND METHODS}

Amphipods were captured at night with pitfall traps, consisting of plastic cups buried flush with the sand and containing 2 to $3 \mathrm{~cm}$ of seawater. Amphipods were maintained at $3^{\circ} \mathrm{C}$ on moist paper towels. Mortality during capture, return to the laboratory and storage of up to several weeks was negligible. MPI and GPI phenotypes did not differ between freshly caught amphipods and those which had been maintained in the laboratory for several weeks.

The locations sampled are shown in figs. 1 and 2 , and sampling dates are listed in table 2(a). The live weight of each individual in the Oregon samples was recorded. The sex of each individual weighing $0.2 \mathrm{~g}$ or more was determined using the enlarged second gnathopod of males; the sex of smaller individuals could not be determined easily.

Vertical polyacrylamide gel electrophoresis was used; gels contained 7 per cent acrylamide monomer and 0.35 per cent bisacrylamide. Gels 

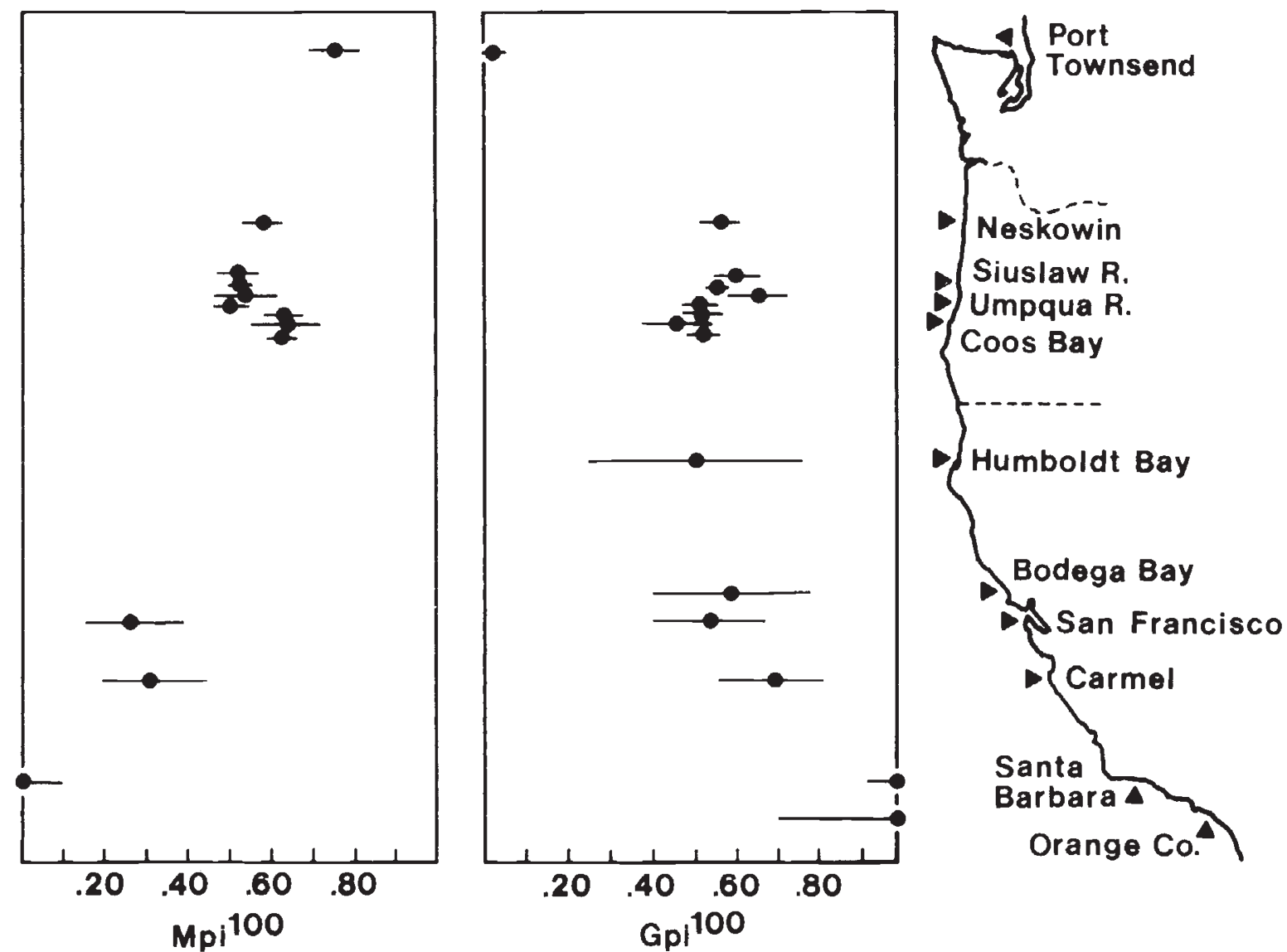

Figure $1 \mathrm{Mpi}^{100}$ and $G p i^{1(10)}$ allele frequencies on the Pacific coast of the United States. Horizontal bars represent 95 per cent confidence intervals.

were run at $3^{\circ} \mathrm{C}$ with $4 \mathrm{~mA}$ of current for 30 minutes followed by $25 \mathrm{~mA}$ for 3 hours. MPI was run on the continuous tris-borate buffer of Ayala et al. (1973) and was detected by the method of Nichols and Ruddle (1973). GPI was run on Poulik's buffer system (Poulik, 1957) and was detected by the method of Shaw and Prasad (1970).

A single leg (or several legs from the smaller individuals) was removed from each amphipod and macerated in about $40 \mu \mathrm{l}$ of distilled water containing 5 per cent sucrose. Each amphipod was then maintained alive for up to a week in a vial with a scrap of moistened paper towel. Another leg was used if there was any ambiguity about the scoring of the MPI or GPI phenotype. For MPI, 5 to $10 \mu \mathrm{l}$ of crude homogenate were loaded into each sample well of the gel, and 1 to $2 \mu$ l samples were used for GPI.

Deviations from Hardy-Weinberg genotype proportions were examined using Wright's inbreeding coefficient $F_{I S}=\left(H_{e}-H_{o}\right) / H_{e}$, where $H_{e}$ is the expected number of heterozygotes, calculated using Levene's (1949) correction for small sample size, and $H_{0}$, is the observed number of heterozygotes. A positive $F_{I S}$ indicates a deficit of heterozygotes relative to Hardy-Weiknberg expectations, and a negative $F_{I S}$ indicates an excess. $\bar{F}_{I S}$, the weighted mean inbreeding coefficient, was calculated using equation (6) of Kirby (1975) for each size class and for the total population samples. This equation takes into account differences in allele frequency among populations in calculating the mean $F_{I S}$. When calculating $\bar{F}_{I S}$ of size classes, only subsamples with 10 or more individuals were used. Statistical significance was tested using $d^{2}=F_{I S}{ }^{2} X$, where $X$ is the number of individuals in the sample; $d^{2}$ is chi-square distributed (Christiansen et al., 1976). The criterion of Cooper (1968) for simultaneous tests was used: to be significant at the 5 per cent 

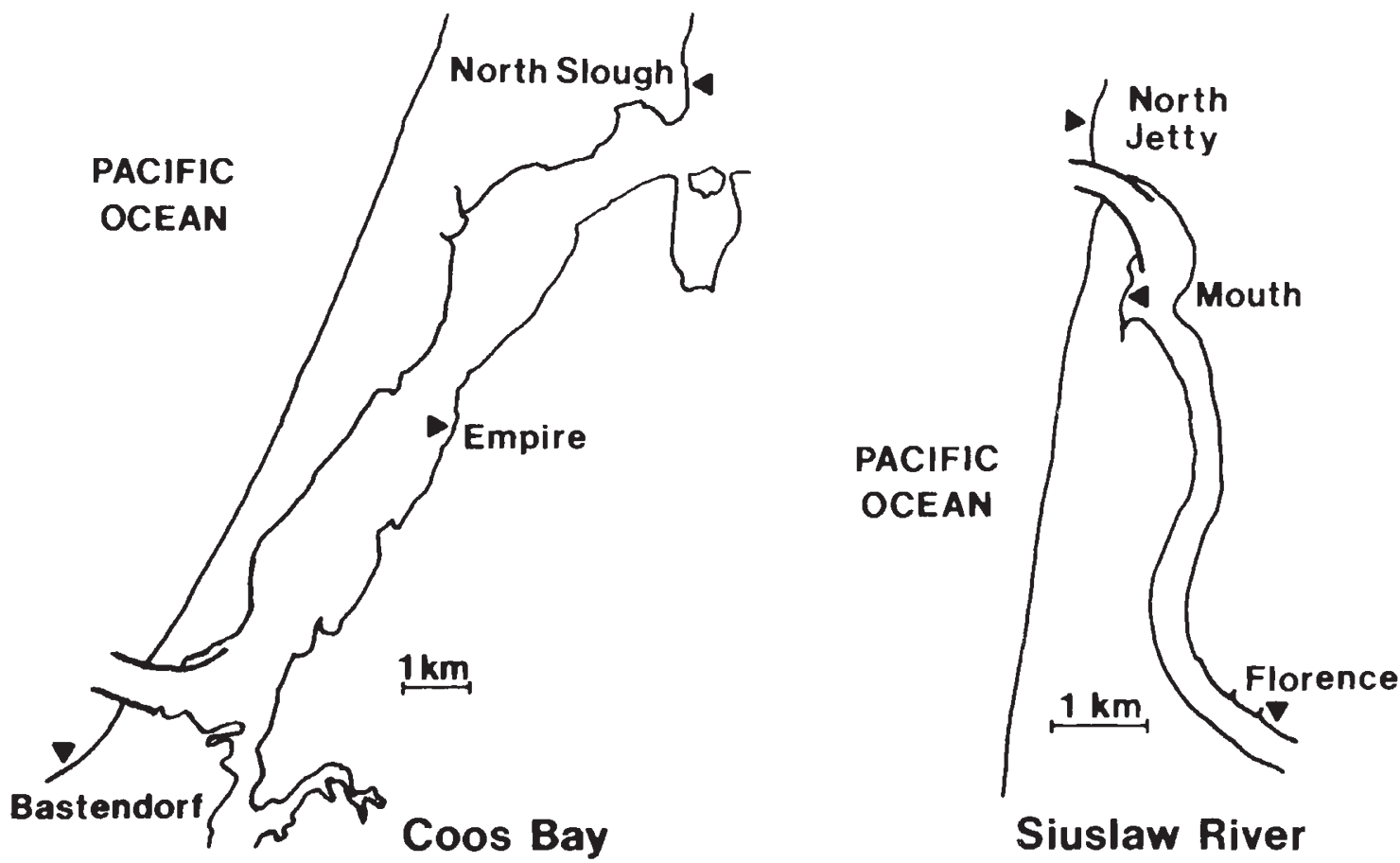

Figure 2 Sample sites at Siuslaw River and Coos Bay, Oregon.

level, one test must have an individual probability less than 0.05 divided by the number of tests.

Variation in allele frequency among size classes was examined by determining the difference in allele frequency between each size class and the remaining size classes. The weighted mean of these deviates was determined over all the population samples. Significance was tested using the method of Cochran (1954; Snedecor and Cochran, 1980, pp. 210-213) with the continuity correction of Mantel and Haenszel (1959). This method was also used to compare allele frequencies of males and

Table $1 M p i$ and $G p i$ allele frequencies. $N$, number of individuals. -, no data. *, $N=40$ for $M p i$

\begin{tabular}{|c|c|c|c|c|c|c|c|c|c|c|c|}
\hline \multirow[b]{2}{*}{ Location } & \multirow[b]{2}{*}{$N$} & \multicolumn{5}{|c|}{ Mpi } & \multicolumn{5}{|c|}{ Gpi } \\
\hline & & 85 & 90 & 96 & 100 & 105 & null & 90 & 95 & 100 & 105 \\
\hline Port Townsend & 93 & & 0.253 & & 0.747 & & & & 0.978 & 0.022 & \\
\hline Neskowin & 209 & $0 \cdot 005$ & 0.419 & 0.002 & 0.574 & & & & 0.433 & 0.567 & \\
\hline Siuslaw-N. Jetty & 162 & & 0.481 & & 0.519 & & & $0 \cdot 003$ & $0 \cdot 392$ & 0.605 & \\
\hline \multicolumn{12}{|l|}{ Siuslaw-Mouth } \\
\hline 28 Feb. & 638 & & 0.479 & & 0.521 & & & $0 \cdot 013$ & 0.418 & 0.567 & 0.002 \\
\hline 15 Aug. & 255 & & 0.484 & & 0.516 & & 0.002 & $0 \cdot 004$ & 0.443 & 0.551 & \\
\hline total & 893 & & 0.480 & & 0.520 & & 0.001 & 0.011 & 0.426 & 0.562 & 0.001 \\
\hline Siuslaw-Florence & 80 & & 0.462 & & 0.538 & & & 0.013 & 0.325 & 0.663 & \\
\hline Umpqua & 238 & 0.002 & 0.498 & & $0 \cdot 500$ & & & 0.008 & 0.473 & 0.519 & \\
\hline Coos-Bastendorf & 289 & 0.002 & 0.377 & & 0.619 & 0.002 & & 0.005 & 0.466 & 0.527 & $0 \cdot 002$ \\
\hline Coos-Empire & 67 & & $0 \cdot 366$ & & 0.627 & 0.007 & & & 0.537 & 0.463 & \\
\hline Coos-N. Slough & 183 & & 0.372 & & 0.626 & 0.003 & & & 0.475 & 0.525 & \\
\hline Humboldt Bay & 8 & & - & & - & & & & $0 \cdot 500$ & $0 \cdot 500$ & \\
\hline Bodega Bay & 12 & & - & & - & & & & 0.417 & 0.583 & \\
\hline San Francisco & 27 & 0.037 & 0.704 & & $0 \cdot 259$ & & & 0.019 & $0 \cdot 444$ & 0.537 & \\
\hline Carmel & 28 & 0.196 & $0 \cdot 500$ & & $0 \cdot 304$ & & & & $0 \cdot 304$ & 0.696 & \\
\hline Santa Barbara & $80^{*}$ & & $1 \cdot 00$ & & & & & & & 0.769 & 0.231 \\
\hline Orange County & 4 & & - & & - & & & & & $1 \cdot 00$ & \\
\hline
\end{tabular}


females. $G$-tests were used to test for heterogeneity of allele frequency among samples (Sokal and Rohlf, 1981).

\section{RESULTS}

MPI phenotypes were either one- or two-banded in both males and females, and GPI phenotypes were either one- or three-banded in both males and females. This is consistent with MPI being a monomer and GPI a dimer, both coded by autosomal loci with codominant alleles, as is the case in other amphipods (Busath, 1980; Bulnheim and Scholl, 1981) and in many other crustaceans (Hedgecock et al., 1982). The common allozyme which migrated furthest towards the anode was designated 100, and other allozymes were named by adding to or subtracting from 100 the mobility difference in millimetres. The genetic loci coding for the enzymes MPI and GPI are designated $\cdot \mathbf{M p i}$ and $G p i$. For statistical purposes, rare alleles were

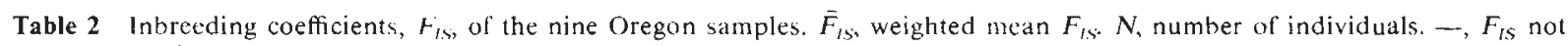
calculated

(a) $F_{I S}$ of $M p i$. Under each size class are listed the number of $M p i^{90 / 90}, M p i^{90 / 100}, M p i^{100 / 100}$, and $F_{I S}$. All sampling dates are 1984

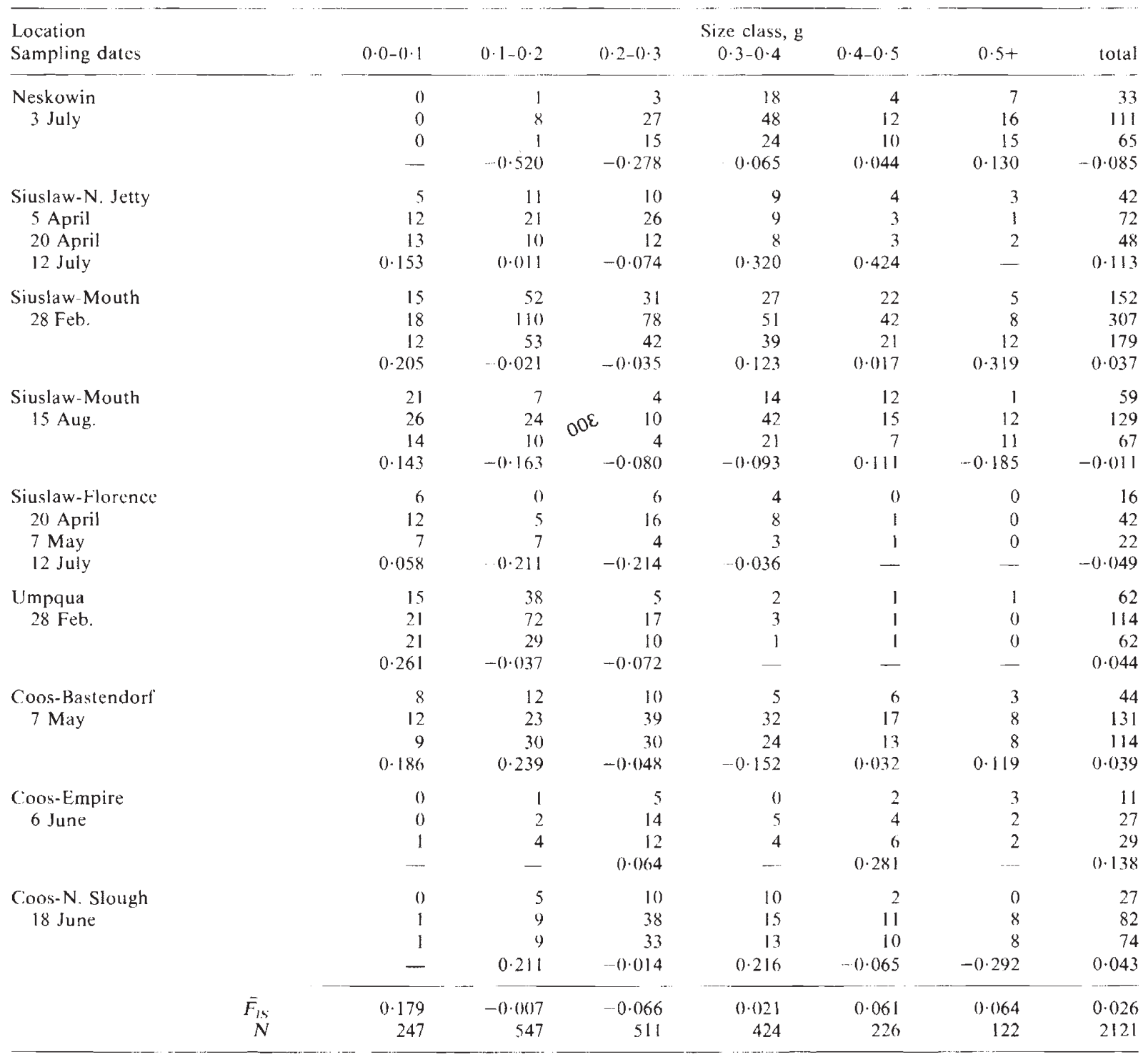


(b) $F_{I S}$ of $G p i$. Under each size class are listed the number of $G p i^{95 / 95}, G p i^{95 / 100}, G p i^{100 / 100}$, and $F_{I S}$

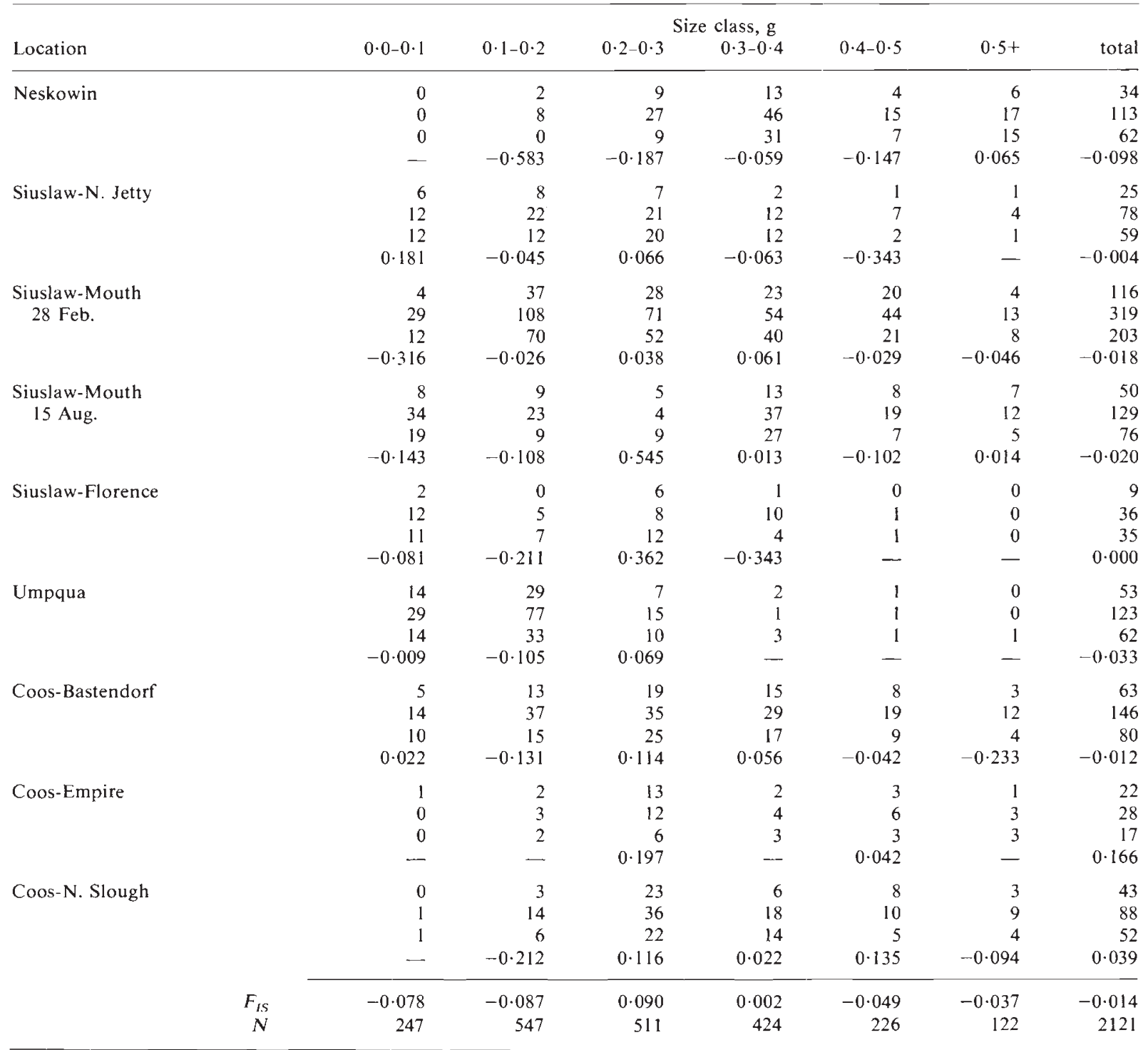

pooled with the alleles for the electrophoretically closest common allozymes. One individual exhibited a two-banded GPI phenotype, which could result from a heterozygote of $G p i^{100}$ and an allele producing an inactive allozyme; the presumed null allele was pooled with $G i^{95}$.

Both the Mpi and Gpi loci showed geographic differences of allele frequency associated with latitude (table 1, fig. 1). $M p^{100}$ and $G p i^{95}$ were greatest in frequency at Port Townsend, Washington, the northernmost location sampled. These alleles were lowest in frequency at Santa Barbara, California, and were intermediate in frequency in Oregon and northern California.
The $M p i$ allele frequencies in nine Oregon samples were significantly heterogeneous ( $G=$ $19 \cdot 20, P<0 \cdot 01)$. The $G p i$ allele frequencies within Oregon were not heterogeneous overall ( $G=9 \cdot 42$, $P>0 \cdot 10)$. The Siuslaw-Mouth sample, from near the mouth of the Siuslaw River estuary (fig. 1), had a significantly lower frequency of the $G p i^{100}$ allele than the Siuslaw-Florence sample, from $6 \mathrm{~km}$ upstream $(G=6.04,0.025>P>0.01)$. No such difference was present at a second estuary, Coos Bay, where the frequencies of $G p i^{100}$ were virtually identical outside the estuary, at Coos-Bastendorf, and $14 \mathrm{~km}$ upstream, at Coos-North Slough. One location, Siuslaw-Mouth, was sampled in February 
and again in August to test for seasonal changes in allele frequency. Neither Mpi nor Gpi allele frequency differed significantly between the two samples (table 1).

Of the nine Oregon samples, none had an inbreeding coefficient, $F_{I S}$, which differed significantly from zero at either locus (table 2). However, when the samples were divided into size classes, the $0 \cdot 0-0 \cdot 1 \mathrm{~g}$ class exhibited a deficit of heterozygotes (positive $\bar{F}_{I S}$ ) at the $M p i$ locus. Because the forces causing deviations from HardyWeinberg proportions would likely affect the two loci differently, the data for each locus were considered a separate set of seven simultaneous tests (the six size classes and the total $\bar{F}_{I S}$ ). The individual probability for the $\bar{F}_{I S}$ of $\mathrm{Mpi}$ in the $0 \cdot 0-0 \cdot 1 \mathrm{~g}$ class was $0 \cdot 005$, which is significant at the 5 per cent level (Cooper, 1968). At the Gpi locus, none of the $\bar{F}_{I S}$ values differed significantly from zero.

Neither Mpi nor Gpi differed significantly in allele frequency between males and females, either in whole population samples or in size classes taken separately. There was no significant sizerelated variation in allele frequency at either locus.

\section{DISCUSSION}

There were differences in allele frquency associated with latitude at both the Mpi and Gpi loci in M. californiana. Latitudinal differences at loci coding for GPI are present in many organisms; there are few reported examples of latitudinal MPI differences, perhaps because MPI is often not included in routine electrophoretic surveys. Selection by differences in temperature or some other environmental variable is often inferred to be the cause of latitudinal differentiation. However, it could also result from random drift in isolated populations followed by migration. On a smaller scale, $M p i$ allele frequencies within Oregon were significantly heterogeneous; the variation was not associated with a known environmental variable.

At the Mpi locus there was a significant deficit of heterozygotes in the smallest size class. Heterozygote deficits are common at enzyme loci in marine animals, and the pattern of heterozygote deficit only in small or young individuals is present in the bivalves Geukensia demissa (= Modiolus demissus) (Koehn et al., 1973), Mytilus californianus (Tracey et al., 1975), Crassostrea virginica (Zouros et al., 1980), and Mytilus edulis (Koehn and Gaffney, 1984) in the fish Rhombosolea plebia (Smith and Francis, 1984), and in the terrestrial isopod Porcellio scaber (Sassaman, 1978). There are a number of possible explanations for a heterozygote deficit, some of which would also explain its presence in only the smallest size class.

\section{Unscored individuals}

Because the phenotype of an Mpi heterozygote consists of two bands rather than one, heterozygotes are more likely to be too faint to score. In the $0 \cdot 0-0 \cdot 1 \mathrm{~g}$ class, five amphipods which could not be reliably scored died or escaped before they could be electrophoresed a second time. Even if all five were heterozygotes, the $\bar{F}_{I S}$ would only be reduced from $0 \cdot 179$ to $0 \cdot 156$.

\section{Mis-scored individuals}

A total of 254 individuals were electrophoresed twice and scored both times for Mpi. In only one case did the second scoring differ from the first, an error rate whch is far too small to account for the observed heterozygote deficit.

\section{Null allele}

To account for the observed $\bar{F}_{I S}$, a null allele would have to have a frequency of at least 0.086 in the smallest size class (Zouros and Krimbas, 1969). The heterozygote deficit is not seen in adults, which implies strong selection against the null allele; the mutation rate then required to recreate the null allele polymorphism in each generation is unrealistically high.

\section{Population mixing}

To produce the observed $\vec{F}_{I S}$ of 0.179 by mixing of differentiated populations would require the equal mixing of populations differing in allele frequency by 0.42 . This is much greater than the range of $M p i$ allele frequencies found in the eight Oregon locations sampled, which suggests that population mixing is not the cause of the heterozygote deficit. The natural history of $M$. californiana also makes it unlikely: migrants from one beach to another would either have to hop overland for considerable distances or get swept to sea and then deposited on another beach, which suggests that immigrants are probably a small proportion of most populations.

\section{Seasonal mixing}

Large seasonal changes in allele frequency, with subsequent mixing of individuals selected on dur- 
ing different seasons, are unlikely; at the $M p i$ locus there was no significant difference in allele frequency between February and August.

\section{Cryptic species}

Inadvertent sampling of two species, with the two species differing in allele frequency, can also be dismissed. Of the three other Megalorchestia species known in Oregon, only $M$. benedicti shares its MPI and GPI allozymes with $M$. californiana (J.H. McDonald, unpublished). $M$. benedicti is monomorphic for $\mathrm{Mpi}^{90}$ in Oregon (McDonald 1984). Adult $M$. benedicti, which are easily recognized, were found only at the Siuslaw-North Jetty site, so inadvertent sampling of $M$. benedicti might explain the heterozygote deficit in only one of the six samples where it was found.

\section{Non-random sampling}

If heterozygous individuals spent less time hopping about, they would have been less likely to fall into the pitfall traps used in this study. Most of the samples were collected between dusk and midnight; if heterozygotes emerged from their burrows in the early morning they would also be less likely to get sampled. Behavioral differences related to enzyme genotypes have been suggested for the fish species Gymnocephalus cernua (Nyman, 1975) and Fundulvs heteroclitus (DiMichele and Powers, 1982), the isopod Asellus aquaticus (Christensen, 1977), and Colias butterflies (Watt et al., 1983).

\section{Assortative mating}

Assortative mating with respect to the $M p i$ locus could occur if different $M p i$ genotypes bred at different times, or through a combination of sizeassortative mating and size-related variation in allele frequency. If assortative mating is the cause of the heterozygote deficit, strong selection favoring heterozygotes would also be required to explain the lack of deficit in the larger size classes.

\section{Selection against heterozygotes}

Viability selection against heterozygotes might produce the heterozygote deficit. Selection would have to favour heterozygotes in older amphipods in order to erase the deficit in larger size classes. Reversing selection at different life stages has been postulated to explain heterozygote deficits in bivalves (Singh and Green, 1984; Zouros and Foltz, 1984).

\section{Faster growing heterozygotes}

In a number of studies of organisms in which the age of the individuals is known, heterozygotes grow faster than homozygotes (Mitton and Grant, 1984). The amphipods in this study were divided into size, not age, classes. If $M p i$ heterozygotes grow faster than homozygotes, heterozygotes would spend less time in the smallest size class and thus a heterozygote deficit would result.

There are four plausible explanations for the deficiency of $\mathrm{Mpi}$ heterozygotes in the smallest size class: assortative mating, followed by selection favoring heterozygotes; selection against heterozygotes, followed by selection favoring heterozygotes; non-random sampling caused by genotype related differences in behavior; or genotype related differences in growth rate.

Acknowledgment This work is a result of research sponsored (in part) by the Oregon State University Sea Grant College Program supported by NOAA Office of Sea Grant, U.S. Department of Commerce, under grant number NA81 AA-D-00086, Project No. R/CP-18. The U.S. Government is authorized to produce and distribute reprints for governmental purposes notwithstanding any copyright notation that may appear hereon.

\section{REFERENCES}

AYALA, F. J., HEIXGECOCK, D., ZUMWALT, G. S. AND VALEN TINE, J. W. 1973. Genetic variation in Tridacna maxima, an ecological analog of some unsuccessful evolutionary lineages. Evolution, 27, 177-191.

BOUSFIELD, F. L. 1982. The amphipod superfamily Talitroidea in the northeastern Pacific region. I. Family Talitridae: systematics and distributional ecology. Natn. Mus. Natur. Sci. (Otiawa) Publ. Biol. Oceanogr., 11, 1-73.

BOWERS, D. E. 1964. Natural history of two beach hoppers of the genus Orchestoidea (Crustacea: Amphipoda) with reference to their complemental distribution. Ecology, 45, $677-696$

BULNHEIM, H.P. AND SC.HOLL, A. 1981. Electrophoretic approach to the biochemical systematics of gammarids. Helgolander Meeresunters., 34, 391-400.

BUSATH, A. L. 1980. Genetic differentiation of the semi-terrestrial amphipod Orchestia traskiana in an expanded habitat on Santa Cruz Island. In Power, D. M. (ed.) The California Islands: Proceedings of a multidisciplinary symposium. Santa Barbara, California, Santa Barbara Museum of Natural History, pp. 395-401.

CHRISTENSEN, B. 1977. Habitat preference among amylase genotypes in Asellus aquaticus (Isopoda, Crustacea). Hereditas, 87, 21-26.

(CHRISTIANSEN, F. B., FRYDENBERG, O., HJORTH, J. P. ANI) SIMONSEN, V. 1976. Genetics of Zoarces populations. IX. Geographic variation at the three phosphoglucomutase loci. Hereditas, 83, 245-256.

COCHRAN, W. G. 1954. Some methods for strengthening the common chi ${ }^{2}$ tests. Biometrics, 10, 417-451. 
COOPER, D. W. 1968. The significance level in multiple tests made simultaneously. Heredity, 23, 614-617.

DIMICHELE, L. AND POWERS, D. A. 1982. Physiological basis for swimming endurance differences between LDH-B genotypes of Fundulus heteroclitus. Science, 216, 1014-1016.

HEDGECOCK, D., TRACEY, M. L. AND NELSON, K. 1982. Genetics. In Abele, L. G. (ed.) The biology of crustacea, Vol. 2: Embryology, morphology, and genetics. New York, Academic Press, pp. 283-403.

KIRBY, G. C. 1975. Heterozygote frequencies in small subpopulations. Theor. Popul. Biol., 8, 31-48.

KOEHN, R. K., AND GAFFNEY, P. M. 1984. Genetic heterozygosity and growth rate in Mytilus edulis. Mar. Biol, 82, 1-7.

KOFHN, R. K., TURANO, F. J. ANI) MITTON, J. B. 1973. Population genetics of marine pelecypods. II. Genetic differences in microhabitats of Modiolus demissus. Evolution, 27, 100105.

I.F.VI:NE, H. 1949. On a matching problem arising in genetics. Ann. Math. Statist., 20, 91-94.

MANTEL, N. AND HAENSZEL, W. 1959. Statistical aspects of the analysis of data from retrospective studies of disease. J. Natn. Cancer Inst., 22, 719-748.

MCCI.URKIN, J. 1. JR. 1953. Studies on the Genus Orchestoidea (Crustacea: Amphipoda) in California. Ph.D. Thesis, Stanford University, Palo Alto, California.

MCDONAlD, J. H. 1984. Ecological Genetics of Two Polymorphic Enzymes in Three Species of Megalorchestia (Amphipoda: Talitridae). M.S. Thesis, Oregon State University, Corvallis, Oregon.

MITTON, J. B. AND GRANT, M. C. 1984. Associations among protein heterozygosity, growth rate and developmental homeostasis. Annu. Rev. Ecol. Syst., 15, 479-499.

NICHOLS, E. A. AND RUDDLE, F. H. 1973. A review of enzyme polymorphism, linkage and electrophoretic conditions for mouse and somatic cell hybrids in starch gels. $J$. Histochem. Cytochem., 21, 1066-1081.

NYMAN, L. 1975. Allelic selection in a fish (Gymnocephalus cernua (L.)) subjected to hotwater effluents. Rep. Inst. Freshw. Res. Drottningholm, 54, 75-82.
P()UI.IK, M. D. 1957. Starch gel electrophoresis in a discontinuous system of buffers. Nature, 180, 1477-1479.

SASSAMAN. C. 1978. Dynamics of a lactate dehydrogenase polymorphism in the wood louse Porcellio scaber Latr.: evidence for partial assortative mating and heterosis in natural populations. Genetics, 88, 591-609.

SHAW, C. R. AND PRASAD, R. 1970. Starch gel electrophoresis of enzymes-a compilation of recipes. Biochem. Gent., 4, 297-320

SINGH, S. M. AND GREEN, R. H. 1984. Excess of allozyme homozygosity in marine molluscs and its possible biological significance. Malacologia, 25, 569-581.

SMITH, P. J. AND FRANC:IS, R. I. C. C. 1984. Glucosephosphate isomerase genotype frequencies, homozygous excess and size relationships in the sand flounder Rhombosolea plebeia. Mar. Biol., 79, 93-98.

SNEDECOR, G. W. AND COCHRAN, W. G. 1980. Statistical methods. Ames, Iowa: Iowa State Univ. Press. 507 pp.

SOKAL, R. R. AND ROHLF, F. J. 1981. Biometry. San Francisco, W. H. Freeman, 859 pp.

TRACEY, M. L., BFI.LET, N. F. AND GRAVEM, C. D. 1975. Excess allozyme homozygosity and breeding population structure in the mussel Mytilus californianus. Mar. Biol., 32, 303-311.

WAIT, W. B., C.ASSIN, R. C. AND SWAN, M. S. 1983. Adaptation at specific loci. III. Field behavior and survivorship differences among Colias PGI genotypes are predictable from in vitro biochemistry. Genetics, 103, 725-739.

ZOUROS, E. AND D. W. FOLTZ. 1984. Possible explanations of heterozygote deficiency in bivalve molluscs. Malacologia, $25,583-591$.

zOUROS, E. AND KRIMBAS, (. B. 1969. The genetics of Dacus oleae. III. Amount of variation at two esterase loci in a Greek population. Genet. Res., 14, 249-258.

ZOUROS, E., SINGH, S. M. AND MILES, H. E. 1980. Growth rate in oysters: an overdominant phenotype and its possible explanations. Evolution, 34, 856-867. 